\title{
Phenylacetylglutamine May Replace Urea as a Vehicle for Waste Nitrogen Excretion ${ }^{1}$
}

\author{
SAUL W. BRUSILOW \\ Department of Pediatrics, The Johns Hopkins University School of Medicine, Baltimore, Maryland 21205
}

\begin{abstract}
Phenylacetylglutamine (PAG), the amino acid acetylation product of phenylacetate (or phenylbutyrate after $\beta$-oxidation) was evaluated as a waste nitrogen product in patients with inborn errors of urea synthesis. A boy with carbamyl phosphate synthetase deficiency receiving a low nitrogen intake excreted $80-90 \%$ of administered phenylacetate or phenylbutyrate as PAG. The amount of PAG nitrogen excreted varied from $38-44 \%$ of his dietary nitrogen, similar to the relationship between urea nitrogen and dietary nitrogen found in normal subjects receiving low dietary nitrogen. With few exceptions, neither phenylacetate nor phenylbutyrate accumulated in plasma. Treatment with relatively high dose phenylacetate or phenylbutyrate $(0.5-0.6 \mathrm{~g} / \mathrm{kg} / \mathrm{d})$ resulted in normal daytime levels of glutamine. These data suggest that PAG may replace urea as a waste nitrogen product when phenylbutyrate is administered at a dose that yields PAG nitrogen excretion equal to $40-44 \%$ of a low nitrogen intake. (Pediatr Res 29: 147150, 1991)
\end{abstract}

\section{Abbreviations}

PAG, phenylacetylglutamine

The physiologic problem faced by a patient with inborn errors of urea synthesis is excretion of waste nitrogen, i.e. dietary nitrogen not used for net protein synthesis or excreted in other ways (stool, skin, etc.). Treatment of such patients by modifying the quantity and quality of nitrogen intake may reduce the requirements for urea synthesis and thereby be helpful (especially in patients with significant residual ureagenic capacity). Dietary therapy alone has been unsuccessful in severely affected patients $(1,2)$.

That other nitrogen-containing compounds may substitute for urea nitrogen may be adduced from the report by Lewis (3), who described a stoichiometric relationship between the decrease in urine urea nitrogen and appearance of urine hippurate nitrogen in a normal subject given sodium benzoate.

The use of amino acid acylation pathways has been successfully exploited in empiric studies of patients with inborn errors of urea synthesis $(4,5)$. Treatment with sodium benzoate $(0.25 \mathrm{~g} / \mathrm{kg} / \mathrm{d})$ and sodium phenylacetate $(0.25 \mathrm{~g} / \mathrm{kg} / \mathrm{d})$, respectively, activate the synthesis and excretion of hippurate and PAG, both of which may serve as waste nitrogen products. The degree to which

Received May 11, 1990; accepted September 19, 1990.

Correspondence and reprint requests: Dr. Saul Brusilow, The Johns Hopkins Hospital, Park 301, 600 N. Wolfe Street, Baltimore, MD 21205.

Supported by the National Institutes of Health Grants No. HD 11134, HD 26358, and RR 00052, The U.S. Food and Drug Administration Grant no. FD-R000198, The T.A. and M.A. O'Malley Foundation, and the Kettering Family Foundation.

'Presented in part at the Annual Meeting of the American Pediatric Society, Washington, D.C., May 2-5, 1989. hippurate nitrogen and/or PAG nitrogen can substitute for urea nitrogen in patients receiving low nitrogen intakes has not been studied.

We propose to examine the hypothesis that PAG nitrogen alone can replace urea nitrogen as a vehicle for waste nitrogen synthesis and excretion in patients on low protein intakes.

Theoretical considerations. To estimate the requirement for hippurate and/or PAG nitrogen synthesis and excretion, it is necessary to know urine urea nitrogen excretion in normal subjects as a function of dietary nitrogen.

Although there are many studies of the effect of variations of dietary nitrogen intake or urine nitrogen excretion, there are, curiously, very few such studies where urine urea nitrogen has been measured in normal subjects receiving varying nitrogen intakes.

Calloway and Margan (6) reported that on dietary nitrogen intakes $(\mathrm{g} / \mathrm{d})$ of $6.5-7.5(40.6-46.9 \mathrm{~g}$ of protein/d) normal adult males excreted $3.16 \pm 0.3 \mathrm{~g} / \mathrm{d}$ of urea nitrogen, approximately $47 \%$ of their dietary nitrogen. Assuming complete conversion to its amino acid conjugate, the oral administration of $18 \mathrm{~g}$ of sodium phenylacetate should result in the excretion of $3.23 \mathrm{~g}$ of PAG nitrogen, an amount that would completely replace urea nitrogen as a vehicle for waste nitrogen excretion in subjects receiving low protein intakes.

There appear to be no studies of normal children receiving varying nitrogen intakes in whom urine urea nitrogen excretion was measured. However, it is possible to calculate from a report of Waterlow (7) that children (6-24 mo of age) receiving a diet of $0.2 \mathrm{~g} / \mathrm{kg} / \mathrm{d}$ of nitrogen $/ \mathrm{d}(1.25 \mathrm{~g} / \mathrm{kg} / \mathrm{d}$ of protein) excrete 0.094 $\mathrm{g}$ of urea nitrogen $/ \mathrm{kg} / \mathrm{d}, 47 \%$ of dietary nitrogen. To excrete $0.094 \mathrm{~g} / \mathrm{kg} / \mathrm{d}$ of PAG nitrogen would require $0.524 \mathrm{~g} / \mathrm{kg} / \mathrm{d}$ of sodium phenylacetate. This represents a $36 \%$ improvement in nitrogen excretion as compared to the combination of sodium benzoate and sodium phenylacetate, each at a dose of $0.25 \mathrm{~g} / \mathrm{kg} /$ $\mathrm{d}$, which would result in the excretion of $0.069 \mathrm{~g} / \mathrm{kg} / \mathrm{d}$ of nitrogen ( $0.025 \mathrm{~g}$ as hippurate nitrogen and $0.045 \mathrm{~g}$ as PAG nitrogen).

These theoretical considerations suggest that, on a molar basis, phenylacetate (mol wt, 158) is twice as effective as benzoate because PAG contains two nitrogen atoms as compared to the one nitrogen atom of hippurate. Phenylacetate, however has a disadvantage as consequence of its offensive odor [it is one of several phenylalkanoic acids, apart from phenylbutyric acid, secreted as a defensive weapon by the stinkpot turtle (8)]. Therefore, sodium phenylbutyrate (mol wt, 186), which is known to be $\beta$-oxidized in vivo to phenylacetate (9), may serve as a prodrug for phenylacetate.

\section{MATERIALS AND METHODS}

Three studies were performed. In the first, the stoichiometry between oral sodium phenylacetate or sodium phenylbutyrate administration and PAG excretion was studied in a $71 / 2$-yr-old, $27.2-\mathrm{kg}$ boy with carbamyl phosphate synthetase deficiency. During three 3 -d periods (each separated by a 24-h transition period), he respectively received $10 \mathrm{~g}(63.3 \mathrm{mmol})$ of sodium 
Table 1. Urinary excretion of $P A G$ during three 3-d periods during which 71/2-y-old boy with carbamyl phosphate synthetase deficiency was treated with sodium salts of phenylacetate and phenylbutyrate $(g / 3 d)$

\begin{tabular}{lccr}
\hline & Period I & Period II & Period III \\
& Na phenylacetate & Na phenylbutyrate & Na phenylbutyrate \\
\hline g/3 d & 30 & 36 & 42 \\
Predicted PAG excretion (mmol) & 190 & 193 & 225 \\
Measured PAG excretion (mmol) & 157 & 174 & 181 \\
Measured PAG & $93 \%$ & $90 \%$ & $80 \%$ \\
Predicted PAG & & $42 \%$ & $44 \%$ \\
PAG-N $\times 100 *$ & $38.1 \%$ & & \\
\hline Dietary N & & & \\
\hline
\end{tabular}

* Also shown is a calculation of the percentage of dietary nitrogen excreted as PAG nitrogen (PAG-N).

Table 2. Partition of urinary nitrogen in patient described in Table 1

\begin{tabular}{lccc}
\hline & $\begin{array}{c}\text { Period I } \\
(3 \mathrm{~d})\end{array}$ & $\begin{array}{c}\text { Period II } \\
(3 \mathrm{~d})\end{array}$ & $\begin{array}{c}\text { Period III } \\
(3 \mathrm{~d})\end{array}$ \\
\hline Total $\mathrm{N}(\mathrm{g})$ & 8.96 & 9.67 & 9.89 \\
Urea N $(\mathrm{g})$ & 1.05 & 1.75 & 0.94 \\
$\mathrm{NH}_{4}{ }^{+} \mathrm{N}(\mathrm{g})$ & 0.36 & 0.30 & 0.29 \\
\hline
\end{tabular}

phenylacetate, $12 \mathrm{~g}(64.5 \mathrm{mmol})$ of sodium phenylbutyrate, and $14 \mathrm{~g}(75.2 \mathrm{mmol})$ of sodium phenylbutyrate. His daily diet during the three periods consisted of $11 \mathrm{~g}$ of natural protein, $11 \mathrm{~g}$ of an essential amino acid mixture (nitrogen density $12 \%$ ), and $4.5 \mathrm{~g}$ $(25.7 \mathrm{mmol})$ of citrulline. The total nitrogen intake was calculated to be $3.84 \mathrm{~g}$, which included $0.4 \mathrm{~g}$ of nitrogen in the gelatin capsules containing the drugs and the one third of administered citrulline nitrogen that enters the free amino acid pool. Total urinary nitrogen, urea nitrogen, and ammonium nitrogen were measured in each period.

In the second study, the overnight fasting plasma levels of phenylacetate, phenylbutyrate, and PAG were measured in patients with various urea cycle disorders receiving varying dosages of sodium phenylbutyrate.

In the third study, the diurnal variation in plasma levels of glutamine, phenylacetate, phenylbutyrate, PAG, and ammonium was studied in five patients with deficiencies of carbamyl phosphate synthetase or ornithine transcarbamylase, four of whom were treated with phenylaceate or phenylbutyrate.

Plasma levels of phenylacetate and PAG were measured by reverse phase HPLC (Waters, Milford, MA) after precipitation with methanol. The technique includes isocratic elution using the mobile phase of $0.005 \mathrm{M}$ phosphoric acid in $10 \%$ methanol at a flow rate of $1.2 \mathrm{~mL} / \mathrm{min}$ with spectrophotometric detection at $218 \mathrm{~nm}$. Urine levels were similarly measured after appropriate dilution. The detection limits in plasma and urine for phenyl- butyrate, phenylacetate, and PAG were $0.05,0.03$, and 0.02 $\mathrm{mmol} / \mathrm{L}$, respectively.

Phenylbutyrate levels in plasma were also similarly measured except for the mobile phase, which consisted of $0.005 \mathrm{~mol} / \mathrm{L}$ phosphoric acid in $40 \%$ methanol. PAG (for use as an external standard) was synthesized from phenylacetyl chloride and glutamine (10). Plasma amino acids were measured by automated column chromatography (model 6300; Beckman, Palo Alto, CA). Urinary creatinine was measured by the Jaffe reaction after absorption and elution from Lloyds reagent (11). Plasma ammonium was measured by visible spectrophotometry using the indophenol reaction after separation of the ammonium ion by a batch cation exchange technique (12). Urine glucuronides were measured using the naptharesorcinol reagent (13). Urinary nitrogen was measured by the Kjeldahl method previously described (14) and urinary urea and ammonium were measured as described by Chaney and Marbach (15).

These studies were approved by The Johns Hopkins Joint Committee on Clinical Investigation.

\section{RESULTS}

Table 1 compares the stoichiometry between phenylacetate or phenylbutyrate administration and urinary excretion of PAG. The amount of PAG excreted was a function of phenylacetate or phenylbutyrate dose; between 80 and $90 \%$ of the predicted amount of PAG synthesized is excreted. That these may be minimum excretion values is suggested by the coefficient of variation of the creatinine excretion over the $9 \mathrm{~d}$, which was $14 \%$. Table 1 also demonstrates that when PAG excretion is expressed as PAG nitrogen, it accounts for at least $38-44 \%$ of dietary nitrogen intake. Phenylacetate, phenylbutyrate, or total glucuronide excretion in the urine did not exceed $1 \%$ of the administered drug in any period.

Table 2 shows the excretion of total urinary nitrogen, urea

Table 3. Overnight fasting plasma levels of phenylbutyrate, phenylacetate, and PAG in 10 patients receiving various doses of sodium phenylbutyrate*

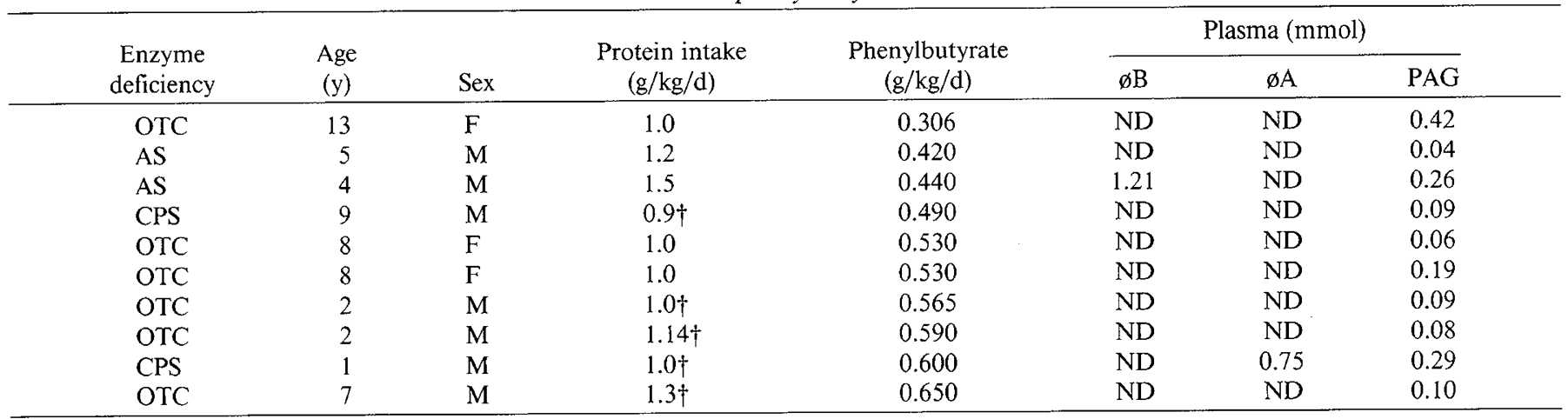

${ }^{*} \varnothing \mathrm{B}$, phenylbutyrate; $\varnothing \mathrm{A}$, phenylacetate; OTC, ornithine transcarbamylase; AS, argininosuccinic acid synthetase; CPS, carbamyl phosphate synthetase; ND, not detectable.

$\dagger$ Protein intake consisted of approximately equal amounts of natural protein and an essential amino acid mixture. 


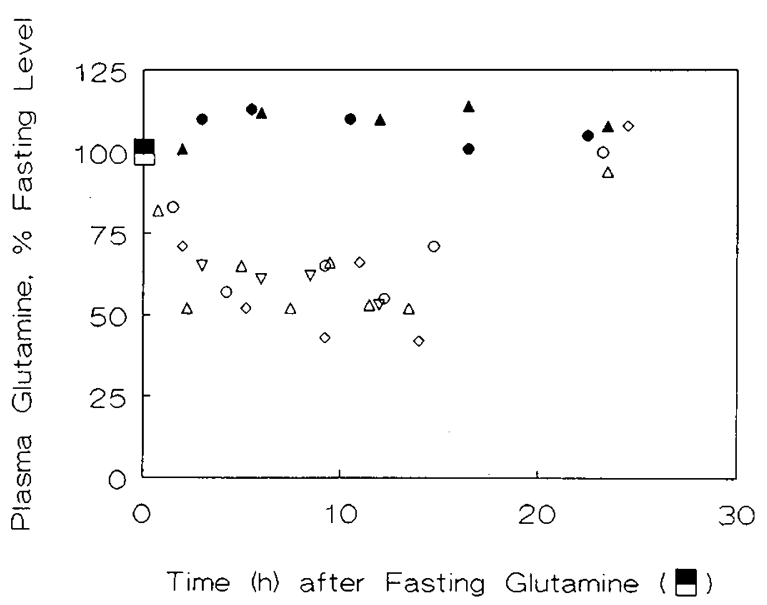

Fig. 1. Plasma glutamine levels expressed as a percent of overnight fasting level $(\boldsymbol{D}, 100 \%)$ measured at time 0 (between 0730 and 0930) in five patients with inborn errors of urea synthesis. Drugs were given in three to four divided doses. OTC, ornithine transcarbamylase; CPS, carbamyl phosphate synthetase; Na $\phi \mathrm{A}$, sodium phenylacetate; Na $\phi \mathrm{B}$, sodium phenylbutyrate.

\begin{tabular}{clcll}
$\begin{array}{r}\text { Fasting } \\
\text { glutamine }\end{array}$ & $\begin{array}{c}\text { Enzyme } \\
\text { deficiency }\end{array}$ & Age $(\mathrm{y})$ & Sex & \multicolumn{1}{c}{$\begin{array}{c}\text { Treatment } \\
(\mathrm{g} / \mathrm{kg})\end{array}$} \\
\hline O 1.30 & OTC & 4 & $\mathrm{~F}$ & NaøB, 0.490 \\
$\triangle 0.67$ & CPS & 7 & $\mathrm{M}$ & NaøB, 0.565 \\
$\nabla 1.26$ & OTC & 7 & $\mathrm{M}$ & NaøB, 0.600 \\
$\diamond 1.21$ & OTC & 9 & $\mathrm{~F}$ & NaøA, 0.500 \\
-1.03 & OTC & 12 & $\mathrm{~F}$ & None \\
$\boldsymbol{\Delta} 1.11$ & OTC & 48 & $\mathrm{~F}$ & None \\
\hline
\end{tabular}

nitrogen, and ammonium nitrogen in each of the 3-d periods, during which he received between 11 and $12 \mathrm{~g}$ of dietary nitrogen and $13.5 \mathrm{~g}(77.1 \mathrm{mmol})$ of citrulline.

To evaluate whether phenylacetate, phenylbutyrate, or PAG accumulate, overnight fasting plasma levels were measured in 10 patients receiving oral sodium phenylbutyrate at doses varying from 0.306 to $0.65 \mathrm{~g} / \mathrm{kg} / \mathrm{d}$ (Table 3 ). With only two exceptions, overnight fasting plasma levels of phenylbutyrate and phenylacetate were below the limits of detectability. Plasma levels of PAG were below $0.5 \mathrm{mmol} / \mathrm{L}$.

Figure 1 shows the diurnal variation of plasma glutamine level in two untreated females with ornithine transcarbamylase deficiency and four treated patients with a deficiency of either carbamyl phosphate synthetase or ornithine transcarbamylase. Plasma glutamine levels returned to normal during the day in each treated patient regardless of the overnight fasting glutamine levels, which were $0.67,1.31,1.26$, and $1.20 \mathrm{mmol} / \mathrm{L}$ (normal, $0.596 \pm 0.66 \mathrm{mmol} / \mathrm{L}$ ). The plasma glutamine level remained unchanged at high levels $(>1 \mathrm{mmol} / \mathrm{L})$ in the two untreated patients.

In patients receiving sodium phenylbutyrate, the mean $( \pm 1$ SD) diurnal plasma levels of phenylacetate, phenylbutyrate, and PAG (excluding overnight fasting values described earlier) were $0.37 \pm 0.3,0.17 \pm 0.25$, and $1.42 \pm 0.91 \mathrm{mmol} / \mathrm{L}$, respectively. For the patient who received only sodium phenylacetate, the mean $( \pm \mathrm{SD})$ diurnal plasma levels of phenylacetate and PAG were (excluding overnight fasting levels) $0.88 \pm 0.49$ and $0.79 \pm$ $0.48 \mathrm{mmol} / \mathrm{L}$, respectively. Excluding overnight fasting values, the range of plasma levels of phenylacetate, phenylbutyrate, and PAG were $0.026-1.87,0-0.872$, and $0.093-3.15 \mathrm{mmol} / \mathrm{L}$, respectively. Throughout the day, the mean plasma ammonium level for the four treated patients was $25.5 \pm 3.3 \mu \mathrm{mol} / \mathrm{L}$, range 20-34 (upper limit of normal, <30).

\section{DISCUSSION}

Examination of the stoichiometry between sodium phenylacetate or phenylbutyrate administration and the excretion of PAG as shown in Table 1 demonstrates both that phenylbutyrate appears to be completely oxidized to phenylacetate and that phenylacetate is completely, or nearly so, conjugated with glutamine.

That complete conjugation of the drugs occurs may be further adduced by the insignificant amount of unchanged drugs or their esters in urine and by the lack of accumulation in overnight fasting plasma (Table 2).

Table 1 also shows the relationship between PAG nitrogen excretion and dietary nitrogen. At doses of sodium phenylbutyrate of 0.441 and $0.515 \mathrm{~g} / \mathrm{kg} / \mathrm{d}, 1.62$ and $2.88 \mathrm{~g} / \mathrm{d}$ of PAG nitrogen were excreted representing at least 42 and $44 \%$ of dietary nitrogen. When compared to the relationship between urea nitrogen excretion in normal adults or children receiving low nitrogen intakes, it appears that PAG nitrogen may serve as a replacement vehicle for waste nitrogen synthesis and excretion in children with little or no ability to synthesize urea.

That this patient synthesized little or no urea may be inferred by comparing urinary urea excretion (Table 2) with citrulline intake. Urinary urea nitrogen excretion in each 3-d period varied from $0.94 \mathrm{~g}$ (33 mmol urea) to $1.75 \mathrm{~g}$ (62.5 mmol urea), all of which can be accounted for by the normal metabolic fate of the supplementary dietary citrulline in each period $(77.1 \mathrm{mmol})$.

It has been apparent for a number of years that hyperammonemia in patients with inborn errors of urea synthesis is always associated with high plasma glutamine levels $(1,16)$. It also has been shown in such patients that plasma glutamine levels increase before the onset of symptomatic hyperammonemia (17). Figure 1 suggests that phenylacetate or phenylbutyrate are effective in maintaining normal nitrogen homeostasis as manifested by maintenance of plasma glutamine levels at normal or near normal levels during the day without significant accumulation of drugs or their reaction products.

Our data support the hypothesis that high doses of phenylacetate or phenylbutyrate will result in the synthesis and excretion of PAG nitrogen similar to the amount of urea nitrogen that is excreted in normal subjects on a low-protein diet. Unlike urea synthesis, which will increase or decrease in proportion to nitrogen intake, PAG nitrogen synthesis is a function of the dose of phenylacetate or phenylbutyrate. Therefore, the appropriate dose will be a function of dietary nitrogen and nitrogen retention. Under circumstances of avid nitrogen retention (e.g. premature or full-term infants and patients on marginal nitrogen intakes) it may be possible to induce negative nitrogen balance by administering high-dose phenylacetate or phenylbutyrate. For example, a nutritionally stable 6 -y-old boy with ornithine transcarbamylase deficiency receiving an essential amino acid diet developed alopecia, periorbital edema, and hypoproteinemia shortly after phenylbutyrate was substituted for benzoate (unpublished observations). His nutritional deficiencies promptly resolved when protein was added to his diet.

Whether phenylacetate or phenylbutyrate may be helpful in the management of other nitrogen accumulation diseases, such as hepatic encephalopathy or chronic renal disease, remains to be tested. Although both the liver and the kidney have the requisite enzyme activity for glutamine conjugation $(18,19)$, phenylacetyl CoA ligase and acyl-CoA:L-glutamine N-acyl-transferase, it is not certain that either organ alone will have the requisite activity or, in the case of chronic renal disease, whether PAG accumulation may limit the usefulness of these drugs.

Acknowledgments. The author thanks Ellen Gordes and Evelyn Bull for their excellent technical assistance and also thanks the staff of the Pediatric Clinical Research Center for nursing support.

\section{REFERENCES}

1. Shih VE 1976 Hereditary urea cycle disorders. In: Grisolia S, Baguena R, Major R (eds) The Urea Cycle. John Wiley, New York, pp 367-414 
2. Brusilow SW, Batshaw ML, Waber LJ 1979 The use of keto-acids in inborn errors of urea synthesis. In: Winick M (ed) The Nutritional Management of Genetic Disorders. John Wiley, New York, pp 67-75

3. Lewis HB 1914 Studies in the synthesis of hippuric acid in the animal organisms. II. The synthesis and rate of elimination of hippuric acid after benzoate ingestion in man. $\mathbf{J}$ Biol Chem 18:225-231

4. Brusilow SW, Tinker T, Batshaw ML 1980 Amino acid acylation: a mechanism of nitrogen excretion in inborn errors of urea synthesis. Science 207:659661

5. Brusilow SW, Horwich A 1989 Urea cycle enzymes. In: Scriver C, Beaudet A, Sly W, Valle D (eds) The Metabolic Basis of Inherited Disease, 6th Ed. McGraw-Hill, New York, pp 629-664

6. Calloway DH, Margan S 1971 Variation in endogenous nitrogen excretion and dietary nitrogen utilization as determinants of human protein requirements. J Nutr 101:205-216

7. Waterlow JC 1963 The partition of nitrogen in the urine by malnourished Jamaican infants. Am J Clin Nutr 12:235-240

8. Eisner T, Conner WE, Hicks K, Dodge KR, Rosenberg HI, Jones TH, Cohen M, Meinwald J 1977 Stink of stinkpot turtle identified: phenylalkanoic acids. Science 196:1347-1349

9. Knoop F 1905 Der abbau aromatischer fettsaure tierkorper. Beitr Chem Physiol Path 6:105-162

10. Thierfelder H, Sherwin CP 1915 Phenylacetylglutamin und sein Bildung in menschlichen Korpen nach Eingabe von Phenyleissegsaure. Hoppe-Seyler Zeit Physiol Chem 94:1-9

11. Van Pilsum JF 1959 Determination of creatinine and related guanidium compounds. Methods Biochem Anal 7:193-251

12. Brusilow SW, Batshaw ML, Waber LJ 1982 Neonatal hyperammonemiac coma. Adv Pediatr 29:69-103

13. Nir I 1964 Determination of glucuronic acid by naptharesorcinol. Anal Biochem 8:20-23

14. Brusilow SW, Tinker J, Batshaw ML 1980 Amino acid acylation: a mechanism of nitrogen excretion in inborn errors of urea synthesis. Science 207:659661

15. Chaney AL, Marbach EP 1971 Modified reagents for determination of urea and ammonia. Clin Chem 8:130-132

16. Levin B 1971 Hereditary metabolic disorders of the urea cycle. Adv Clin Chem 14:65-163

17. Batshaw ML, Walser M, Brusilow SW 1980 Plasma alpha-ketoglutarate in urea cycle enzymopathies and its role as a harbinger of hyperammonemic coma. Pediatr Res 97:1316-1319

18. Webster LT, Siddiqui VA, Lucas SV, Strong JM, Mieyal JJ 1976 Identification of separate acyl-CoA: glycine and acyl-CoA: L-glutamine N-acyl-transferase activities in mitochondrial fractions from liver of rhesus monkey and man. J Biol Chem 251:3352-3358

19. Moldave K, Meister A 1957 Synthesis of phenylacetylglutamine by human tissue. J Biol Chem 229:463-476 